\title{
Validation of a Four-Factor Measurement Model of the Health Promoting Lifestyle Profile-II: a Confirmatory Study with Kenyan Undergraduate Students
}

\author{
Oloo Micky Olutende ${ }^{1 *}$, Prof. Edwin K. Wamukoya ${ }^{1}$, Dr. Maximilla N. Wanzala ${ }^{2}$ \\ ${ }^{1}$ Department of Health Promotion and Sports Science, Masinde Muliro University of Science and Technology \\ ${ }^{2}$ Department of Public Health, Masinde Muliro University of Science and Technology
}

DOI: $10.36348 /$ sjnhc.2019.v02i12.001

| Received: 05.12.2019| Accepted: 15.12.2019 | Published: 18.12.2019

*Corresponding author: Oloo Micky Olutende

\section{Abstract}

Due to the rise of unhealthy lifestyles among the young population, there is a need to develop a tool to assess their healthpromoting behavior. Despite the importance of this issue, few studies have explored the Health-Promoting Lifestyle Profile (HPLP) among students, and literature from the East African region for this particular group is even more scarce. Objective. The main aim of this study was to validate a four-factor structure measurement model of the Health-promoting lifestyle Profile-II (HPLP-II) based on CFI, SRMR, and RMSEA among Kenyan undergraduate students Design. The study design was a cross-sectional analytical, that utilized quantitative methods Setting. The study was conducted in Kakamega County, located in Western Kenya. Analysis. Data were analyzed through confirmatory factor analysis, which was conducted using robust maximum likelihood estimation. The factor model was tested for validity and construct validity. Main outcome measures. Subscales physical activity, nutrition, interpersonal relationship and stress management of the Health-Promoting Lifestyle Profile II Results. After omission of some items due to high correlation with variables in the same factor, a final 34 item model was analyzed. The overall 34-item tool had a Cronbach's alpha of 0.79 indicating good reliability. The factors physical activity, stress management, nutrition, and interpersonal relationship had Cronbach coefficients of $0.70,0.80,0.81$ and 0.83 respectively. All the correlations were below the recommended cut-off point of 0.85 , which indicated that the four-health promoting behavior factors achieved good discriminant validity. The RMSEA index was less than $.08, \mathrm{RMSEA}=0.07,90 \% \mathrm{CI}=[0.07,0.08]$, which is indicative of a good model fit. The SRMR was between .05 and .08 , SRMR $=0.08$, which implies that the model fits the data adequately, however the CFI (CFI=0.81 which is less than 0.9) and chi-square goodness of fit test (was significant $\chi^{2}(318)=686.69$, $p<.001$, ) indicated poor model fit. Conclusion. In conclusion, within the limitations of this study, the results showed that confirmatory factor analysis yielded a partially good final measurement model. This study recommended that further research should examine the replicability of the HPLP-II in more diverse Kenyan speaking populations.

Keywords: Confirmatory factor analysis, Discriminant validity, Construct validity, Health-promoting behaviors, HealthPromoting Lifestyle Profile-II, Non-communicable diseases, University students, Kakamega, Kenya.

Copyright @ 2019: This is an open-access article distributed under the terms of the Creative Commons Attribution license which permits unrestricted use, distribution, and reproduction in any medium for non-commercial use (NonCommercial, or CC-BY-NC) provided the original author and source are credited.

\section{BACKGROUND}

A healthy lifestyle is one of the imperative factors affecting the health of an individual. [1]. Health is a complex process that continuously changes throughout the life of an individual and is considered more than freedom from disease and illness, though freedom from disease is essential for optimal health. In Kenya, research shows that unhealthy lifestyles have been a growing problem over the years (World Health Organization[WHO] [2], Machio [3]. In 2012 Noncommunicable diseases (NCDs) accounted for more than $50 \%$ of total hospital admissions and over $55 \%$ of hospital deaths in Kenya (Kenya Health Management Information System [HMIS] [4]. According to Kenya Demographic and Health Survey [KDHS] report [5], over $61 \%$ of the population in Kenya did not engage in exercise that caused an increase in their heart rate for at least 10 minutes continuously at work or during other activities. In the Western region of Kenya, results showed that $39.1 \%$ of women and $45.4 \%$ of men did not engage in PA at all [6]. These findings corroborate with studies done in other parts of the world that showed most adults worldwide did not engage in PA at levels with the potential to yield benefits $[7,8]$. Regardless of the literature documenting the benefits of a healthy 
lifestyle as well as the potential negatives related to not adopting it, students have been found to typically follow unhealthy lifestyles, particularly in ignoring physical activity and responsibility for health $[9,10]$.

University students are in a dynamic transition period of growth and development that bridges adolescence (high school students) and adulthood (people in the community). This period sees many rapid changes in the body and mind and in social relationships [11]. At this stage, there are various difficult life conditions and different lifestyles in the university environment. With the changes in study style and unfamiliar life conditions, many students engage in a wide range of unhealthy habits, such as inadequate nutritional intake, rest, and exercise [12, 13]. Research showed that unhealthy lifestyles are widespread among young adults and they suffered from poor dietary habits $[14,15]$. A systematic review examined the associations of physical activity (PA) and sedentary behavior to childhood overweight and obesity from the last ten years showed that sedentary behaviors were positively associated with weight status [16]. University students represent a large proportion of the youth population [17]. The association of a lousy diet and lack of exercise as everyday habits among university students was confirmed by a literature review about healthy lifestyles among university populations[18]. Many university students have more choices in health-related behaviors and are more prone to unhealthy lifestyles, shifting toward smoking, unhealthy nutrition, increased stress, and a sedentary lifestyle [19]. According to a recent study, it is stated that the students who are more indulge in physical activity are likely to score more grades in academics as compared to those who are leading a sedentary lifestyle [20].

Due to the rise of unhealthy lifestyles among the young population, there is a need to develop a tool to assess their health-promoting behavior. Despite the importance of this issue, few studies have explored the Health-Promoting Lifestyle Profile (HPLP) among students, and literature from the East African region for this particular group is even more scarce. The HPLP-II has been used extensively in health-promotion research and is reported to have sufficient validity and reliability for use in different societies and populations, including university students [21, 22]. Various studies have attempted to test and validate HPLP-II among university students. However most of these studies are from American, Asian, and European contexts [23-25]. Testing of validity and reliability of translated instruments is necessary because adaptation of a health behavior instrument to different populations requires not only language but linguistic, environmental, and cultural adjustment [26]. The Health Promoting Lifestyle Profile-II (HPLP-II) [27] was developed to measure the multicomponent of healthy lifestyles. It was a revision of the HPLP scale [28] based on Nola Pender's health promotion model. The model identifies background factors (e.g. individual characteristics and experiences and behavior-specific cognitions) that influence health behavior. Health-promoting behavior the desired behavioral endpoint or outcome of health decision-making and preparation for action [29]. This tool has also been used to further explore the impact of students' gender [30], years of study [31, 32] and their health-promoting behaviors. The majority of previous studies reported the validation results based on exploratory factor analysis and/or confirmatory factor analysis and internal consistency reliability based on Cronbach's alpha coefficient. Validation in terms of confirmatory factor analysis (CFA) was not reported in the original English version HPLP-II instrument [27]. Therefore, the present study sought to validate a fourfactor structure measurement model of the HPLP-II based on CFI, SRMR, and RMSEA among Kenyan undergraduate students.

\section{METHODS}

This was a cross-sectional study; surveys were conducted between January and May 2019. Sampling was conducted by the convenience sampling method, and university students at the campus at the time of data collection were sampled. The eligibility criteria were as follows: I) must be a university student; II) able to communicate in writing; III) Kenyan nationality; IV) provided informed consent to participate in the study. Exclusion criteria were lack of consent, the inability to complete the questionnaires due to any reasons put forth and participation in other research studies. No further approval was needed since the project did not require access to patients or personal data. All participants were informed of the complete confidentiality of the data and were notified of the subsequent handling of the data following analysis.

\section{Participants}

The study population was university students in a Kenyan public university. A wide range of recommendations regarding sample size in factor analysis has been made. Some authors [33] suggest that 100 respondents are the absolute minimum number to be able to undertake factor analysis. Others would suggest that an adequate sample size for confirmatory factor analysis (CFA) considered $n \geq 200$ [34]. There is also a rule of thumb of five respondents per item [35]. For this study the researchers opted for 4 participants per item. Hence it was necessary to recruit at least 208 students $(4 \times 52$ items $)$. The majority were female $(80.3 \%, \mathrm{n}=167)$. The majority were below age 21 years. The mean age of the participants was 21 years old (SD $=1.3)$. Most of the participants were first years $(33 \%$, $\mathrm{n}=68)$.

\section{Measures}

The HPLP II is a 52-item 4-point Likert scale (never, sometimes, often, and routinely) tool based on Pender's health promotion model which contains 6 subscales [19]; self-realization (SR) (9 items), health 
responsibility (HR) (9 items), physical activity (PA), 8 items), nutrition $(\mathrm{N}) \quad(9$ items), interpersonal relations(IR)(9 items) and stress management SM) (8 items). The HPLP-II focuses on self-initiated actions and perceptions that serve to maintain or enhance the level of wellness, self-actualization, and fulfillment of the individual [19]. The HPLP-II has been translated into different languages and widely used in other studies [24, 36, 25]. The internal consistency Cronbach alpha for the original English version of HPLP-II was satisfactory, with 0.94 for the total scale of HPLP-II, and from 0.79 to 0.87 for its six subscales [27]. A validity and reliability study concerning HPLP II in Turkey was carried out by Bahar et al. [37], who used 52 items. The HPLP II was translated from English to Turkish by Bahar et al. [38] Cronbach Alpha coefficient of the HPLP II was 0.92 and had high reliability. The reliability coefficient was 0.77 for the sub-scale health responsibility, 0.79 for physical activity, 0.68 for nutrition, 0.79 for self-realization, 0.80 for interpersonal relationships, and 0.64 for stress management[38].

Question numbers of subscale related to Physical activity subscale included $4,10,16,22,28,34$, 40, 46 substances in HPLP II. This subscale consists of 8 items, points that can be taken at the lowest score is " 8 ", the highest is " 32 ". The numbers of questions in HPLP II related to the nutrition subscale are 2, 8, 14, 20, 26, 32, 38, 44, and 50. This subscale includes nine items and can take the values of 9 and 36 as its min and max values. The numbers of questions of interpersonal relationships subscale in HPLP II are 1, 7, 13, 19, 25, $31,37,43$, and 49 and have the lowest and highest values of 9 and 36, respectively. The stress management subscale includes 8 questions in HPLP II. The numbers of items are 5, 11, 17, 23, 29, 35, 41, and 47 and have the min and max of 8 and 32, respectively.

\section{DATA ANALYSIS}

Statistical analyses were conducted using SPSS software version 25 and AMOS software. Frequency analyses were used to identify missing values in each variable. The total score was obtained by summing the responses to all the items in. The same procedure was adopted for all the subscales scores. All questionnaires included in the study were completed without any missing values. Multivariate normality assumption was checked, and results indicated that the data did not meet the assumption, based on Mardia multivariate skew $(p<0.001)$ and kurtosis $(p<0.001)$ tests. Therefore, for the subsequent confirmatory factor analysis (CFA), the robust maximum likelihood estimator (MLR) was utilized, as this is robust to nonnormality. To achieve good psychometric characteristics, high standardized factor loadings (> $0.40)$ are preferred [39]. Therefore, items with factor loadings less than 0.40 were examined and treated as potentially problematic items. Problematic items would be omitted only with adequate theoretical support. According to Hair et al., reporting various fit indices are necessary because there are no standard rules for assessment of model fit [10]. Based on the 6-factor structure and 52-item measurement model in the present study, the fit indices and its acceptable threshold value are as follows: the comparative fit index (CFI) and Tucker and Lewis index (TLI) with the desired value of more than 0.90; the root mean square error of approximation (RMSEA) with the desired value of less than 0.08; probability RMSEA with the desired value of more than 0.05 ; and the standardized root mean square (SRMR) with the desired value of less than 0.08 [40]. The construct reliability (CR) in a latent variable modeling approach was calculated for each factor in HPLP-II-M based on CR formula listed in a published study by Raykov and Marcoulides in 2015. The acceptable value of CR is above 0.70 [40]. Discriminant validity was checked by inspecting the correlation between the factors in the model. Discriminant validity is established when the correlation between factors is below 0.85 . Also, to determine the internal consistency, Cronbach's alpha coefficient was used. Accepted values for Cronbach's alpha coefficient and ICC 0.7 are more considered $[41,42]$.

\section{RESULTS}

Demographic summary statistics were calculated for each interval and ratio variable. Frequencies and percentages were calculated for each nominal variable. The most frequently observed category of Gender was Female $(n=167,80 \%)$. The most frequently observed category of Age groups was 21 years or below $(n=138,66 \%)$. The most frequently observed category of Year was First Year $(n=68$, $33 \%$ ). Frequencies and percentages are presented in Table 1.

Table-1: Frequency Table for Nominal Variables

\begin{tabular}{|l|l|l|}
\hline Variable & $n$ & $\%$ \\
\hline Gender & & \\
\hline Female & 167 & 80.29 \\
\hline Male & 41 & 19.71 \\
\hline Age groups & & \\
\hline 22 years or above & 70 & 33.65 \\
\hline 21 years or below & 138 & 66.35 \\
\hline Year & & \\
\hline Second Year & 50 & 24.04 \\
\hline Third Year & 41 & 19.71 \\
\hline First Year & 68 & 32.69 \\
\hline Fourth-year & 49 & 23.56 \\
\hline
\end{tabular}

Note. Due to rounding errors, percentages may not equal $100 \%$.

The observations for Age had an average of $20.98\left(S D=1.29, S E_{M}=0.09\right.$, Min $=19.00$, Max $=$ 24.00, Skewness $=0.30$, Kurtosis $=-0.95, M d n=21.00$, Mode $=20.00)$. When the skewness is greater than 2 in absolute value, the variable is considered to be asymmetrical about its mean. When the kurtosis is greater than or equal to 3 , then the variable's distribution is markedly different than a normal distribution in its tendency to produce outliers [43]. 
Table-2: Reliability analysis

\begin{tabular}{|l|l|l|l|l|}
\hline Scale & No. of Items & $\boldsymbol{\alpha}$ & Lower Bound & Upper Bound \\
\hline Physical activity & 8 & 0.70 & 0.63 & 0.76 \\
\hline Stress Management & 8 & 0.80 & 0.75 & 0.84 \\
\hline Nutrition & 9 & 0.81 & 0.77 & 0.85 \\
\hline Interpersonal Relationship & 9 & 0.83 & 0.79 & 0.87 \\
\hline Overall & 34 & 0.79 & 0.74 & 0.83 \\
\hline Note. The lower and upper bounds of Cronbach's $\alpha$ were calculated using a 95.00\% confidence interval. \\
\hline
\end{tabular}

The Cronbach's alpha coefficient was evaluated using the guidelines suggested by George and Mallery (2016) where $>.9$ excellent, $>.8$ good, $>.7$ acceptable, $>.6$ questionable, $>.5$ poor, and $\leq .5$ unacceptable. The items for Physical activity had a Cronbach's alpha coefficient of 0.70 , indicating questionable reliability. The items for Stress management had a Cronbach's alpha coefficient of 0.80 , indicating acceptable reliability. The items for Nutrition had a Cronbach's alpha coefficient of 0.81 , indicating good reliability. The items for Interpersonal relationships had a Cronbach's alpha coefficient of 0.83 , indicating good reliability. Overall the 34-item tool had a Cronbach's alpha of 0.79 , indicating good reliability.

\section{Confirmatory Factor Analysis (CFA)}

CFA model was conducted to determine whether the latent variables, Physical Activity, Nutrition, Interpersonal Relationship, and Stress Management, adequately describe the data. Maximum likelihood estimation was performed to determine the standard errors for the parameter estimates.

\section{Assumptions}

Multivariate normality. To assess the assumption of multivariate normality, the squared Mahalanobis distances were calculated for the data and plotted against the quantiles of a Chi-square distribution $[35,44]$. In the scatterplot, the solid line represents the theoretical quantiles of a normal distribution. Normality can be assumed if the points form a relatively straight line. The scatterplot for normality is presented in Figure 1.

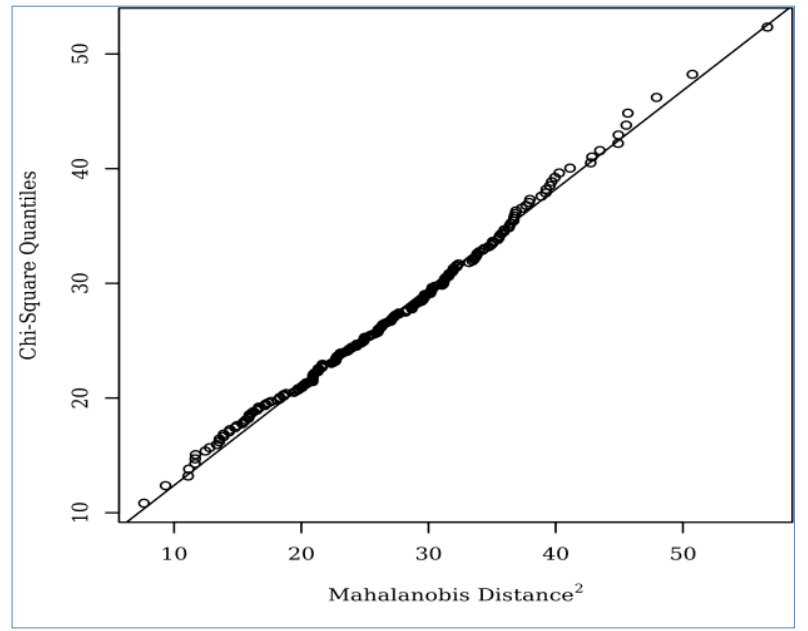

Fig-1: Mahalanobis distance scatterplot testing multivariate normality.

\section{Multivariate Outliers}

To identify influential points in the data Mahalanobis distances were calculated and compared to a $\chi^{2}$ distribution [45]. An outlier was defined as any Mahalanobis distance that exceeds 55.48, the .999 quantile of a $\chi^{2}$ distribution with 27 degrees of freedom [46]. There was 1 observation detected as outliers.

\section{Multicollinearity}

Although variables should be correlated with one another to be considered suitable for factorization, variables that are too highly correlated can cause problems in CFA. To assess multicollinearity, the squared multiple correlations were inspected and the determinant of the correlation matrix was calculated. Any variable with an $R^{2}>.90$ can contribute to multicollinearity in the CFA model [46]. Variables that exhibit high multicollinearity should either be removed from the analysis or combined as a composite variable. There were no variables that had an $R^{2}>90$. Another assessment for multicollinearity is to assess the determinant of the data's correlation matrix. A determinant that is $\leq 0.00001$ indicates that multicollinearity exists in the data [44]. The value of the determinant for the correlation matrix was 0.000018 , indicating that there was no multicollinearity in the data. 


\section{Confirmatory Factor Analysis (CFA) results}

The reliability of the analysis was tested based on the sample size used to construct the model. Next, the results were evaluated using the Chi-square goodness of fit test and fit indices. Lastly, the squared multiple correlations $\left(R^{2}\right)$ for each endogenous variable were examined. The results of the CFA model are presented in Table 7. The node diagram is shown in Figure 2.

Table-7: Unstandardized Loadings (Standard Errors), Standardized Loadings, and Significance Levels for Each Parameter in the CFA Model $(\mathrm{N}=207)$

\begin{tabular}{|c|c|c|c|}
\hline Parameter Estimate & Unstandardized & Standardized & $p$ \\
\hline Covariance for Physical Activity and Nutrition & $-0.00(0.00)$ & -0.04 & .661 \\
\hline Covariance for Physical Activity and Interpersonal Relationship & $0.00(0.00)$ & 0.11 & .457 \\
\hline Covariance for Physical Activity and Stress Management & $-0.00(0.00)$ & -0.02 & .859 \\
\hline Covariance for Nutrition and Interpersonal Relationship & $0.01(0.01)$ & 0.07 & .388 \\
\hline Covariance for Nutrition and Stress Management & $-0.01(0.01)$ & -0.06 & .425 \\
\hline $\begin{array}{l}\text { Covariance for Interpersonal Relationship and Stress } \\
\text { Management }\end{array}$ & $-0.00(0.01)$ & -0.03 & .750 \\
\hline Error in Physical Activity & $0.00(0.00)$ & 1.00 & .646 \\
\hline Error in PA1 & $0.37(0.04)$ & 0.99 & $<.001$ \\
\hline Error in PA2 & $0.52(0.06)$ & 0.73 & $<.001$ \\
\hline Error in PA3 & $0.51(0.05)$ & 0.80 & $<.001$ \\
\hline Error in PA4 & $0.46(0.05)$ & 0.73 & $<.001$ \\
\hline Error in PA5 & $0.43(0.05)$ & 0.83 & $<.001$ \\
\hline Error in PA6 & $0.20(0.03)$ & 0.46 & $<.001$ \\
\hline Error in PA7 & $0.63(0.06)$ & 0.87 & $<.001$ \\
\hline Error in PA8 & $0.25(0.03)$ & 0.65 & $<.001$ \\
\hline Error in Nutrition & $0.17(0.05)$ & 1.00 & $<.001$ \\
\hline Error in N2 & $0.49(0.05)$ & 0.74 & $<.001$ \\
\hline Error in N3 & $0.16(0.02)$ & 0.37 & $<.001$ \\
\hline Error in N4 & $0.17(0.02)$ & 0.53 & $<.001$ \\
\hline Error in N5 & $0.59(0.06)$ & 0.98 & $<.001$ \\
\hline Error in N6 & $0.07(0.01)$ & 0.18 & $<.001$ \\
\hline Error in N8 & $0.71(0.07)$ & 0.64 & $<.001$ \\
\hline Error in N9 & $0.14(0.02)$ & 0.25 & $<.001$ \\
\hline Error in Interpersonal Relationship & $0.14(0.04)$ & 1.00 & $<.001$ \\
\hline Error in IR2 & $0.48(0.05)$ & 0.77 & $<.001$ \\
\hline Error in IR3 & $0.09(0.02)$ & 0.21 & $<.001$ \\
\hline Error in IR4 & $0.17(0.02)$ & 0.48 & $<.001$ \\
\hline Error in IR5 & $0.51(0.05)$ & 0.97 & $<.001$ \\
\hline Error in IR6 & $0.10(0.02)$ & 0.30 & $<.001$ \\
\hline Error in IR8 & $0.73(0.08)$ & 0.67 & $<.001$ \\
\hline Error in Stress Management & $0.18(0.05)$ & 1.00 & $<.001$ \\
\hline Error in SM2 & $0.56(0.06)$ & 0.76 & $<.001$ \\
\hline Error in SM3 & $0.07(0.02)$ & 0.23 & $<.001$ \\
\hline Error in SM4 & $0.14(0.02)$ & 0.52 & $<.001$ \\
\hline Error in SM5 & $0.45(0.04)$ & 0.90 & $<.001$ \\
\hline Error in SM6 & $0.14(0.02)$ & 0.40 & $<.001$ \\
\hline Error in SM8 & $0.73(0.07)$ & 0.81 & $<.001$ \\
\hline
\end{tabular}

Note. $\chi^{2}(318)=686.69, p<.001 ;--$ indicates the statistic was not calculated due to parameter constraint.

\section{Discriminant validity}

The discriminant validity was checked based on the correlations among the factors. The correlations between the latent variables are presented in Table 8 .
All the correlations were below the recommended cutoff point of 0.85 , which indicated that the four-health promoting behavior factors achieved good discriminant validity. 
Table-8

\begin{tabular}{|l|l|l|l|l|}
\hline Variable & Physical Activity & Nutrition & Interpersonal Relationship & Stress Management \\
\hline Physical Activity & 1.00 & -- & -- & -- \\
\hline Nutrition & -0.04 & 1.00 & -- & -- \\
\hline Interpersonal Relationship & 0.11 & 0.07 & 1.00 & -- \\
\hline Stress Management & -0.02 & -0.06 & -0.03 & 1.00 \\
\hline
\end{tabular}

Correlation Table for the Latent Variables

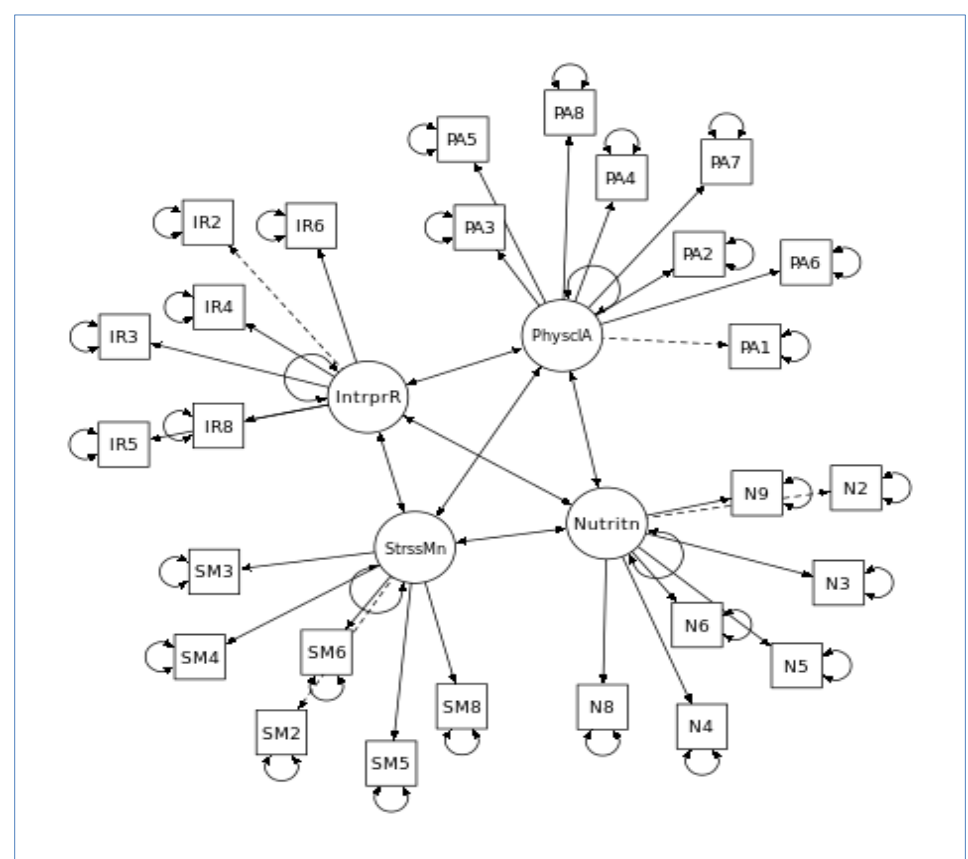

Fig-2: Node diagram for the CFA model

Evaluating sample size. Factor analysis requires a large sample size to construct repeatable and reliable factors. A variety of authors suggest different benchmarks to determine a sufficient sample size for CFA. Some authors use benchmarks based on overall sample size. A common rule of thumb for determining sufficient sample size is 300 observations [44, 22]. Other authors use the ratio $(N: q)$ of overall sample size to the number of free parameter estimates (latent variable, indicator, variance, covariance or any regression estimates) included in the model. Kline [46] recommends that the $N: q$ ratio should be about 20 to 1 . Schreiber, Nora, Stage, Barlow, and King [47] suggest that the consensus for a sufficient $N: q$ ratio is $10: 1$. On the lower end of the ratio, Bentler and Chou [48] suggest that an acceptable $N: q$ ratio is $5: 1$. The participant to item ratio for this analysis was approximately 3 to 1 , where sample size was 207 and the number of variables included was 60 . According to the $N: q$ ratio rule-of-thumb, the given sample size is insufficient for CFA, however this doesn't limit use of the test.

Model fit. There are a variety of ways to measure if the CFA model adequately describes the data. The Chi-square statistic is the most popular statistic used to measure the model fit. Besides the Chisquare statistic, fit indices are also used to help researchers determine if the factor analysis model fits the data properly. Along with the Chi-square goodness of fit test, the following fit indices were used to assess the model fit: root mean square error of approximation (RMSEA), comparative fit index (CFI), Tucker-Lewis index (TLI) and standardized root mean square residual (SRMR).

Goodness of fit test. A Chi-square goodness of fit test was conducted to determine if the CFA model fits the data adequately. It is standard practice for CFA to include the Chi-square test. However, this test is sensitive to sample size, which causes the test to almost always reject the null hypothesis and indicate a poor model fit when the sample size is large [49]. The results of the Chi-square goodness of fit test were significant, $\chi^{2}(318)=686.69, p<.001$, suggesting that the model did not adequately fit the data.

Fit indices. The RMSEA index was less than $.08, \mathrm{RMSEA}=0.07,90 \% \mathrm{CI}=[0.07,0.08]$, which is indicative of a good model fit [49]. The CFI was less than $.90, \mathrm{CFI}=0.81$, suggesting that the model is indicative of a poor model fit [49]. The TLI was less than .95 , TLI $=0.79$, which is indicative of a poor model fit [49]. The SRMR was between .05 and .08, SRMR $=0.08$, which implies that the model fits the data adequately [49]. The fit indices are presented in Table 9. 
Table-9: Fit Indices for the CFA model

\begin{tabular}{|l|r|r|r|r|}
\hline NFI & TLI & CFI & RMSEA & SRMR \\
\hline 0.70 & 0.79 & 0.81 & 0.07 & 0.08 \\
\hline
\end{tabular}

Note. RMSEA $90 \% \mathrm{CI}=[0.07,0.08] ;$-- indicates that the statistic could not be calculated.

\section{Squared multiple correlations}

The individual relationship between each indicator variable and the latent variable can be assessed by the observed variable's $R^{2}$ value. The $R^{2}$ value identifies how much of the indicator variable's variance explains the factor. An $R^{2}$ value $\leq .20$ suggests that the observed variable does not adequately describe the factor and should be considered for removal from the model [49]. The following observed variables had $R^{2}$ values $\leq .20:$ PA1, PA5, PA7, N5, IR5, SM5, and SM8. The $R^{2}$ values, along with the error variances for each observed variable are presented in Table 10.

\section{Table-10: Estimated Error Variances and $\mathbf{R}^{2}$ Values for Each Indicator Variable - Latent Variable Relationship in the CFA model}

\begin{tabular}{|l|l|l|}
\hline Endogenous Variable & Standard Error & $\boldsymbol{R}^{2}$ \\
\hline PA1 & 0.37 & 0.01 \\
\hline PA2 & 0.52 & 0.27 \\
\hline PA3 & 0.51 & 0.20 \\
\hline PA4 & 0.46 & 0.27 \\
\hline PA5 & 0.43 & 0.17 \\
\hline PA6 & 0.20 & 0.54 \\
\hline PA7 & 0.63 & 0.13 \\
\hline PA8 & 0.25 & 0.35 \\
\hline N2 & 0.49 & 0.26 \\
\hline N3 & 0.16 & 0.63 \\
\hline N4 & 0.17 & 0.47 \\
\hline N5 & 0.59 & 0.02 \\
\hline N6 & 0.07 & 0.82 \\
\hline N8 & 0.71 & 0.36 \\
\hline N9 & 0.14 & 0.75 \\
\hline IR2 & 0.48 & 0.23 \\
\hline IR3 & 0.09 & 0.79 \\
\hline IR4 & 0.17 & 0.52 \\
\hline IR5 & 0.51 & 0.03 \\
\hline IR6 & 0.10 & 0.70 \\
\hline IR8 & 0.73 & 0.33 \\
\hline SM2 & 0.56 & 0.24 \\
\hline SM3 & 0.07 & 0.77 \\
\hline SM4 & 0.14 & 0.48 \\
\hline SM5 & 0.45 & 0.10 \\
\hline SM6 & 0.14 & 0.60 \\
\hline SM8 & 0.73 & 0.19 \\
\hline Note - & \\
\hline
\end{tabular}

Note. -- indicates the statistic could not be calculated

\section{DISCUSSION}

The aim of this study was to establish the validity of four factors of the health-promoting lifestyle profile II tools. This validation was done among Kenyan university undergraduate students. The current study found that the most frequently observed category of Gender was Female ( $n=167,80 \%)$. Consistent with the current study is a study done among Malaysian undergraduate students that found $80.4 \%$ of the participants were female [50]. Females tend to be more interested in matters health compared to males. The current study focused on four factors of the HPLP-II (physical activity, nutrition, interpersonal relationship, and stress management). After omission of some items due to high correlation with variables in the same factor, a final 34 item model was analyzed. A study by Bee, Yee, Wan \& Kok [51] used a final model fit of 21 items from a three-factor structure, and the goodnessof-fit values were shown to be adequate fit after removal of a few items. In their study, item Q25 "Eat breakfast" was found to be problematic item that affected the fitness of the model and was dropped from the scale(ibid). While the current study did not include all six factors of the HPLP-II, some studies have used all six factors in their factor analysis [36]. Previous validation studies of HPLP-II reported varying total number of items that fit the CFA measurement model. For example, based on psychometric properties, PérezFortis et al. [52] retained 44 items for Spanish version, Meihan et al. [36] retained 30 items and 51 items respectively for the Chinese version, while Savarese et al. [53] retained 26 items for the Italian version of the HPLP-II. A study by Kuan, Kue, Abdullah, and Tai [50] in Malaysia retained 50 items in the final measurement model, after removal of two low factor loading items.

The current study found that the overall 34item tool had a Cronbach's alpha of 0.79 indicating good reliability. The factors physical activity, stress management, nutrition, and interpersonal relationship had Cronbach coefficients of 0.70, 0.80,0.81 and 0.83, respectively. In a recent study by Kuan, Kueh, Abdullah, and Tai [50], the reliability was satisfactory, with Cronbach alpha of 0.94 for overall scale, 0.81 for physical activity, 0.77 for nutrition, 0.81 for spiritual growth, 0.73 for interpersonal relations, and 0.74 for stress management. Previous validation-reliability studies [23-25] used internal consistency (Cronbach alpha) to determine the reliability of the constructs and found that the subscales of HPLP-II were reliable, Cronbach alpha more than 0.70. A study in Iran found that Cronbach's alpha of the revised HPLP - II was obtained as 0.78 and for their subscales were in the range of $0.67-0.84$. Intraclass correlation coefficient was obtained 0.79 (95\% confidence interval: $0.59-0.86$, $\mathrm{P}<0.001)$ [54]. The findings of the validity index, construct validity, factor analysis, Cronbach's alpha coefficients, and ICC indications show that the HPLPII -48 is a suitable tool to assess HPB (ibid). Hulme et al. reported the reliability of test-retest of the original version as 0.91 , which is little higher than that of the present study. Also consistent with the findings is a study in a Saudi university that found overall reliability to be excellent, with Cronbach's alpha at 0.91[55]. The HPLP-II was also used previously in Arabic and 
Jordanian community and the Cronbach's alpha coefficients were between 0.70 and 0.88 for the subscales and 0.92 for the total scale in this study (AlKandari et al. [37, 34]. Further confirmation was done by Kadriye \& Bermek [56] who found that the overall coefficient alpha for the HPLP-II was 0.89. It had excellent internal consistency reliability with a Cronbach's alpha of 0.85 and demonstrated perfect testretest reliability ( $\mathrm{ICC}=0.87$ ) (ibid). Generally, these results were consistent with the study conducted using the original English version of HPLP-II with 52 items. The overall reliability scale was reported as 0.94 and reliability for six subscales ranged from 0.79 to 0.87 [19].

This study applied CFA, which is a type of structural equation modeling that deals specifically with measurement models. CFA examines the strength of the relationship between an observed measure and latent variables or factors based on factor loading. CFA requires a strong conceptual foundation to guide the specification and evaluation of the factor model. It can be utilized in psychometric evaluation, detection of method effects, construct validation and also for the evaluation of measurement invariance. Since the factors and items of HPLP-II have been predetermined in previous studies, we conducted only a confirmatory study. Our CFA analysis of HPLPII- M supported the factor structure analysis proposed by the authors of the original HPLP-II. These results are consistent with other studies of the psychometric properties of the HPLP-II in Chinese Malaysian and Spanish samples [50]. In the current study majority of the items in the factors had an unstandardized factor loading of over 0.40 . Consistent with the present study is a study among undergraduate students in Malaysia, which found that the sub-scales of the HPLP showed good psychometric properties and could be used to assess health-promoting behavior among undergraduate students [51]. In their study, all items within the sub-scales showed a factor loading above 0.40 . In the same survey, the convergent validity was indicated by $\mathrm{CR}$ estimates, which ranged from 0.664 to 0.844 . Therefore, adequate convergent validity was noted for HPB scale (ibid). The manner of factors' loading was very similar to that seen in studies in other countries [57].

In the current study, The RMSEA index was less than .08 , RMSEA $=0.07,90 \% \mathrm{CI}=[0.07,0.08]$, which is indicative of a good model fit and the SRMR was between .05 and $.08, \mathrm{SRMR}=0.08$, which implied that the model fits the data adequately [49] however, the Chi-square goodness of fit test and CFI indicated a poor model fit. Previous studies done have all shown a good model fit for the factors of the HPLP-II [36, 63, 50]. With regards to discriminant validity, the current study found that all the correlations were below the recommended cut-off point of 0.85 , which indicated that the four-health promoting behavior factors achieved good discriminant validity. Consistent with the current study, a study in Iran by Tanjani et al. [54] found that Pearson correlation coefficients between the revised HPLP-II and their items were in range of 0.27 0.65. A study in Malaysia found that the final measurement model demonstrated discriminant validity among university students. The strong positive correlations between subscales were evidence of discriminant validity [51,58]. The findings were similar to Sousa et al. [24, 59]'s study which also found significant positive correlations between the construct.

This study cannot be complete without stating the limitations which may have brought about the possible inconsistencies with findings from other studies. The first limitation of this study was the sample size. The participant to item ratio for this analysis was approximately 3 to 1 , where the sample size was 207 , and the number of variables included was 60 . According to the $N: q$ ratio rule-of-thumb, the given sample size was insufficient for CFA. Hence the results may be a bit unreliable. Another limitation is that the four subscales of HPLP-II in this study were tested among undergraduate students. However, we are unsure about its generalization among Kenyan undergraduate students in general until further cross-validation studies are conducted, keeping in view that the environment and the school structure may be closely similar. Another limitation is the use of a self-reported questionnaire, which may be subject to response bias. Participants might have given their socially desired responses. To overcome this limitation, we emphasized the importance of honest feedback to the subjects before data collection. Finally, the cross-sectional design may compromise the ability to generalize the study findings, and the survey design tends to produce superficial rather than in-depth information on a particular phenomenon and therefore suits an extensive rather than intensive analysis.

\section{CONCLUSION \& RECOMMENDATION}

In conclusion, the four-factor HPLP-II structure had good overall reliability and factor reliability. With regards to the final model, the results showed adequate model fit using RMSEA and SRMR, but poor model fit using CFI and chi-square goodness of fit test. The model displayed good discriminant validity as all correlations among the four factors were below 0.85. This study recommends that further research should examine the replicability of the HPLPII in more diverse Kenyan speaking populations. Also, quantitative and qualitative studies are needed to shape a holistic picture of the healthy lifestyle of the students. Furthermore, longitudinal studies are also recommended to gain insight into changes in healthpromoting behaviors of students over time.

\section{ABBREVIATIONS}

CFA: Confirmatory factor analysis; CFI: Comparative fit index; CR: Construct reliability; HPLPII: Health-Promoting Lifestyle Profile II; MLR: Robust 
maximum likelihood estimator; RMSEA: Root mean square error of approximation; SD: Standard deviation; SRMR: Standardised root mean square; TLI: Tuckerlewis index

\section{ACKNOWLEDGMENTS}

We would like to express our gratitude to the respondents. And not to forget the extraordinary efforts of the field staff.

\section{ETHICAL DISCLOSURES}

\section{Protection of human and animal subjects}

The authors declare that the procedures followed were in accordance with the regulations of the relevant research ethics committee and with those of the Code of Ethics of the Declaration of Helsinki.

\section{Confidentiality of data}

The authors declare that they have followed the protocols of the university on the publication of the data.

\section{Right to privacy and informed consent}

The authors have obtained the written informed consent of the patients or subjects mentioned in the article. The corresponding author is in possession of this document.

\section{Competing interest}

The authors declare that they have no competing interests.

\section{Authors\& contributions}

Micky Olutende Oloo and Dr. Maximilla Wanzala conceived the paper, designed and performed the study. Prof Edwin Wamukoya conceived the paper and was the paper's peer reviewer. All authors read and approved the final manuscript.

\section{Funding}

No financial support was provided.

\section{Disclaimer}

The findings and conclusions presented in this manuscript are those of the authors and do not necessarily reflect the official position of Masinde Muliro University of Science and Technology

\section{REFERENCES}

1. Mozaffarian, D., Hao, T., Rimm, E.B., Willett, W.C.\& Hu, F.B. (2011). Changes in diet and lifestyle and long-term weight gain in women and men. N Engl J Med, 364(2), 392-404.

2. World Health Organization. (2017). Preventing Noncommunicable Diseases (NCDs) Reducing Environmental Risk Factors. Retrieved from http://apps.who.int/iris/bitstream/10665/258796/1/ WHO-FWC-EPE-17.01-eng.pdf?ua=1

3. Machio, P. M. (2012). "The Effect of Chronic Illness on Labor Market Outcomes in Kenya."
Center for the Study of Africa Economies. Oxford, UK. https://editorialexpress.com/cgibin/conference/download.cgi?db_name=CSAE201 2\&paper_id=502

4. Kenya Health Management Information system, 2012

5. Kenya National Bureau of Statistics., \& ICF Macro. (2014). Kenya Demographic and Health Survey

6. Grimstvedt, M., Der Ananian, C., Pasquariello, C. D., Masambia, F. M., Chevan, J., Haskvitz, E. M., ...\& Rogers, L. Q. (2013). The role of professional counseling associations in professional counseling practice in Kenya. Medicine and Science in Sports and $\quad$ Exercise, 200. https://doi.org/10.2105/AJPH.69.6.591

7. Ding, D., Lawson, K. D., Kolbe-Alexander, T. L., Finkelstein, E. A., Katzmarzyk, P. T., van Mechelen, W. \& Pratt, M. (2016). The economic burden of physical inactivity: a global analysis of major non-communicable diseases. The Lancet, 388(10051), 1311-1324

8. Das, P., \& Horton, R. (2016). PA???time to take it seriously and regularly. The Lancet, 388(10051), 1254-1255. https://doi.org/10.1016/S01406736(16)31070-4

9. Senjam, S., \& Singh, A. (2012). Health promoting behavior among college students in Chandigarh, India. Indian J Commun Health, 24(1), 58-62

10. Mašina, T., Madžar, T.\& Musil, V. (2017). Differences in health promoting lifestyle profile among Croatian medical students according to gender and year of study. Acta Clin Croat,

11. World Health Organization. (1977). Coming of age: from facts to action for adolescent sexual and reproductive health. Geneva: WHO.

12. Fujii, T., Ohsawa, I., Nozawa, A., Mori, K., Kagaya, M. \& Kajioka, T. (1998). The association of physical activity level characteristics and other lifestyle with obesity in Nagoya University alumni, Japan. Scand J Med Sci Sports, 8, 57-62.

13. Teiji, N. (2008). The integration of school nutrition program into health promotion and prevention of lifestyle-related diseases in Japan. Asia Pac J Clin Nutr, 17(S1), 349-51.

14. Alizadeh, M. \& Ghabili, K. (2008). Health related lifestyle among the Iranian medical students. Res $J$ Biol Sci. 3(1), 4-9.

15. Gan, W.Y., Mohd, N.M.T., Zalilah, M.S., \& Hazizi, A.S. (2011). Differences in eating behaviours, dietary intake and body weight status between male and female Malaysian university students. Malays J Nutr, 12(2), 213-28.

16. Prentice-Dunn, H. \& Prentice-Dunn, S. (2012). Physical activity, sedentary behavior, and childhood obesity: a review of cross-sectional studies. Psychol Health Med, 17(3), 255-73.

17. Wang, D., Xing, X.H. \& Wu, X.B. (2013). Healthy lifestyles of university students in China and influential factors. Sci World J, 412950. 
18. Sánchez-Ojeda, M. \& De Luna-Bertos, E. (2015). Healthy lifestyles of the university population. Nutr Hosp, 31(5), 1910-1919.

19. Walker, S., Sechrist, K., \& Pender, N. (1987). The health-promoting lifestyle profile: Development and psychometric characteristic. Nurs Res, 36(2), 76-81.

20. Deliens, T., Clarys, P., Ilse, D.B., \& Benedicte, D. (2013). Weight, socio-demographics, and health behavior related correlates of academic performance in first year University students. Nutrition Journal, 1-9

21. Acton, G.J. \& Malathum, P. (2000). Basic need status of health-promoting self-care behavior in adults. Western Journal of Nursing Research, 22(7), 796-811.

22. Lee, R. \& Loke, A. (2005). Health-promoting behaviours and psychosocial well-being of university students in Hong Kong. Public Health Nursing, 22, 209-220.

23. Pinar, R., Celik, R., \& Bahcecik, N. (2009). Reliability and construct validity of the healthpromoting lifestyle profile II in an adult Turkish population. Nurs Res, 58(3), 184-93.

24. Sousa, P., Gaspar, P., Vaz, D.C., Gonzaga, S. \& Dixe, M.A. (2015). Measuring health-promoting behaviours: cross-cultural validation of the healthpromoting lifestyle profile-II. Int J Nurs Knowl, 26(2), 54-61.

25. Mohamadian, H., Ghannaee, M., Kortdzanganeh, J. \& Lo, M. (2012). Reliability and construct validity of the Iranian version of health-promoting lifestyle profile in a female adolescent population. Int $J$ Prev Med, 4(1), 42-9.

26. Hambleton, R.K., Merenda, P.F., \& Spielberger, C.D. (2004). Issues, designs, and technical guidelines for adapting tests into multiple languages and cultures. Adapting educational and psychological tests for cross-cultural assessment. Mahwah: Lawrence Erlbaum Associates, 15-50.

27. Walker, S.N.\& Hill-Polerecky, D.M. (1996). Psychometric evaluation of the health promoting lifestyle profile II. Unpublished manuscript.

28. Walker, S.N., Sechrist, K.R. \& Pender, N.J. (1987). The health-promoting lifestyle profile: development and psychometric characteristics. Nurs Res, 36(2), 76-81.

29. Pender, N.J. (2011). The health promotion model manual. [cited 2019 Nov 18]. Available from: http://nursing.umich.edu/faculty-staff/ nola-jpender.

30. Peker, K. \& Bermek, G. (2011). Predictors of health-promoting behaviours among freshman dental students at Istanbul University. J Dent Educ, 75(3), 413-420.

31. Wei, C.N., Harada, K., \& Ueda, K. (2012). Assessment of health promoting lifestyle profile in Japanese university students. Environ Health Prev Med, 17(3), 222-227.
32. Hong, J.F., Sermsri, S. \& Keiwkarnka, B. (2007). Health-promoting lifestyles of nursing students in Mahidol University. J Public Health Dev, 5(1), 2740.

33. Bonar, R., Mohammed, S., \& Favaloro, E. J. (2015, April). International normalized ratio monitoring of vitamin $\mathrm{K}$ antagonist therapy: comparative performance of point-of-care and laboratoryderived testing. In Seminars in thrombosis and hemostasis (Vol. 41, No. 03, pp. 279-286). Thieme Medical Publishers.

34. Eshah, N.F. (2011). Lifestyle and health promoting behaviours in Jordanian subjects without prior history of coronary heart disease. International Journal of Nursing Practice, 17, 27-35.

35. Bryman, A., \& Cramer, D. (1997). Quantitative data analysis with SPSS for Windows: A guide for social scientists. Routledge.

36. Meihan, L., \& Chung-Ngok, W. (2011). Validation of the psychometric properties of the healthpromoting lifestyle profile in a sample of Taiwanese women. Qual Life Res, 20(4), 523-8.

37. Al-Kandari, F., Vidal, V., \& Thomas, D. (2008). Health-promoting life-style and body mass index among College of Nursing students in Ku-wait: A correlational study. Nursing and Health Sciences, $10,43-50$.

38. Bahar, O., \& Taherpour, A. (2008, October). Nonlinear dynamic behavior of RC buildings against accelerograms with partial compatible spectrum. In 14th World Conference on Earthquake Engineering., Beijing, China (pp. 1217).

39. Turner, D. S. (2007). Ancient Country: The Historic Character of Rural Devon: a Report on the Devon Historic Landscape Characterisation Project. Devon Archaeological Society.

40. Hair, B. (2006). Babin, \& Anderson.(2010). Multivariate data analysis, 7.

41. de Melo Ghisi, G. L., Grace, S. L., Thomas, S., Evans, M. F., \& Oh, P. (2013). Development and psychometric validation of a scale to assess information needs in cardiac rehabilitation: The INCR Tool. Patient education and counseling, 91(3), 337-343.

42. Ravens-Sieberer, U., Erhart, M., Rajmil, L., Herdman, M., Auquier, P., Bruil, J., ... \& Mazur, J. (2010). Reliability, construct and criterion validity of the KIDSCREEN-10 score: a short measure for children and adolescents' well-being and healthrelated quality of life. Quality of Life Research, 19(10), 1487-1500.

43. Westfall, P. H., \& Henning, K. S. S. (2013). Texts in statistical science: Understanding advanced statistical methods.

44. Field, A. (2013). Discovering statistics using IBM SPSS statistics. sage.

45. Newton, R. R., \& Rudestam, K. E. (2013). Your statistical consultant. Sage. 
46. Kline, R. B. (2015). Principles and practice of structural equation modeling. Guilford publications.

47. Schreiber, J. B., Nora, A., Stage, F. K., Barlow, E. A., \& King, J. (2006). Reporting structural equation modeling and confirmatory factor analysis results: A review. The Journal of educational research, 99(6), 323-338.

48. Bentler, P. M., \& Chou, C. P. (1987). Practical issues in structural modeling. Sociological Methods \& Research, 16(1), 78-117.

49. Hooper, D., \& Coughlan, J. (2008). J., \& Mullen, M.(2008). Structural equation modelling: Guidelines for determining model fit. Electronic Journal of Business Research Methods, 6(1), 5360.

50. Kuan, G., Kueh, Y.C., Abdullah, N., \& Tai, E.L.M. (2019). Psychometric properties of the health promoting lifestyle profile II: cross-cultural validation of the Malay language version. $B M C$ public health, 19, 2-10

51. Bee, C.L., Yee, C.K., Wan, N.A., \& Kok, H.N. (2016). Validation of health promoting lifestyle profile-II: a confirmatory study with a Malaysian undergraduate students' sample. Education in Medicine Journal, 8(2), 65-77.

52. Pérez-Fortis, A., Ulla, D.S.M., Padilla, J.L. (2012). Psychometric properties of the Spanish version of the health-promoting lifestyle profile II. Res Nurs Health, 35(3), 301-13.
53. Savarese, G,, Carpinelli, L., Cavallo, P., \&Vitale, M.P. (2018). Italian psychometric validation of the multidimensional students' health-promoting lifestyle profile scale. Health, 10, 1554-75.

54. Tanjani, P.T., Azadbakht, M., Garmaroudi, G., Sahaf, R. \& Fekrizadeh, Z. (2016). Validity and reliability of health promoting lifestyle profile II in the Iranian elderly. Int J Prev Med, 7, 74.

55. Alzahrani, S.H., Ahmad, A.M., Jamil, B., Saleh, A.S., Musab, M.S., Abdullah, A.A., Mubarak, A.M., Youssouf, S.A. \& Hassan, K.A. (2019). Health-promoting lifestyle profile and associated factors among medical students in a Saudi university. Sage open medicine.

56. Kadriye, P., \& Gülçin, B. (2011). Predictors of Health-Promoting Behaviors Among Freshman Dental Students at Istanbul University. Journal of Dental Education, 75(3), 413-420

57. Haddad, L.G., al-Ma'aitah, R.M., Cameron, S.J. \& Armstrong - Stassen, M. (1998). An Arabic language version of the health promotion lifestyle profile. Public Health Nurs, 15, 74-81.

58. Lo, M. \& Wong, C.N. (2011). Validation of the psychometric properties of the health-promoting lifestyle profile in a sample of Taiwanese women. Qual Life Res, 20, 523-8.

59. Teng, H.L., Yen, M., \& Fetzer, S. (2010). Health promotion lifestyle profile-II: Chinese version short form. $J$ Adv Nurs, 66(8), 1864-73. 